\title{
TANGIBILIZACIÓN DEL ESPÍRITU EMPRENDEDOR Desarrollo de franquicias en el sector de la pequeña y microempresa
}

\author{
MAKING TANGIBLE THE ENTREPRENEURSHIP \\ The development of franchising in the \\ small and micro enterprise sector
}

\author{
Alfonso Gastañaduy Benel ${ }^{1}$
}

\section{RESUMEN}

Cuando se habla de desarrollo económico en países emergentes, generalmente se destaca el papel de las pequeñas y microempresas (mypes), tanto por su capacidad de generación de empleo como por ser la manifestación del espíritu emprendedor de sus gestores. Para ellos se debe desbrozar el camino y plantear opciones prácticas a fin de maximizar el resultado de su trabajo. Es con esta filosofía que este documento plantea la importancia del sistema empresarial de franquicias como medio para optimizar el desempeño de las mypes. ¿Y cómo se puede tener pruebas de tal optimización? Puede haber muchas formas o modalidades, pero mucho destaca el concepto de tangibilización del quehacer empresarial, que evidencia o hace «tocable» el espíritu emprendedor, precisamente el recurso fundamental de gestión de las mypes. Este es el mensaje de fondo: la franquicia es la tangibilización del espíritu emprendedor de las mypes.

Palabras: franquicias, mypes, tangibilización de servicios, espíritu emprendedor.

\begin{abstract}
When talking about economic development in emerging countries, it is generally stressed the role of micro and small enterprises (MSE), both for its ability to generate employment and for being the manifestation of the entrepreneurial spirit of its managers. For them is clearing the way and create practical options to maximize the results of their work. It is with this philosophy that this document raises the importance of the corporate franchises system as a mean to optimize the performance of MSE. And how can we have evidence of such optimization? There can be many ways, but the concept that is becoming more important is how to make tangible the corporate work, which means how to make «touchable» the entrepreneurial spirit, the very critical resource for managing the MSE. This is the message: the franchises make tangible the entrepreneurship spirit of the MSE.
\end{abstract}

Key words: Franchises, MSE, tangible services, entrepreneurial spirit.

1. Universidad ESAN (Perú). Magíster en Administración de la Universidad ESAN.<agastana@esan.edu.pe>. 


\section{INTRODUCCIÓN}

El presente trabajo se focaliza en el desarrollo del entrepreneurship o espíritu emprendedor, con miras a mejorar u optimizar la competitividad internacional de los países de América Latina. En los últimos años, muchos expertos han demostrado que el espíritu emprendedor es la gran base y sustento de esa competitividad. Yendo a los hechos, una de las vías, entre otras, de hacer tangible ese espíritu emprendedor es el formato empresarial de franquicias que, en su base conceptual y práctica, tiene sólidos componentes de emprendedorismo, desarrollo del capital humano y, obviamente, innovación.

Pero la competitividad, al final de cuentas, es un medio; el fin es el desarrollo sostenible. En este razonamiento, además de todos los factores ya tradicionalmente conocidos, se debe considerar que el desarroIlo sostenible tiene tres componentes estructurales: la filosofía (y si se quiere, ideología) de sostenibilidad el desarrollo social sustentable interno o nacional y la competitividad internacional. No obstante, no todo es fácil ni alcanzable de manera inmediata.

Los tomadores de decisiones, tanto gubernamentales como empresariales, deben tener bien claras sus responsabilidades y los retos a los que deben enfrentarse en un mundo en permanente cambio. Los primeros, siguiendo la gran ruta ya iniciada en las últimas décadas (privatización, desregulación y promoción de la inversión privada); los segundos, reforzando y multiplicando sus esfuerzos innovadores para atender debidamente las necesidades de la sociedad (estudio permanente de los mercados, orientación al consumidor y, por ende, una mejor gestión empresarial con visión de protección sostenible del medio ambiente).

En tal sentido, a continuación se presenta una visión panorámica de la situación internacional para, sobre esa base, plantear la propuesta de desarrollo del sistema de franquicias como una de las formas estratégicas y básicas de tangibilización del espíritu emprendedor: de carácter innovador, que genera empleo y desarrolla el capital humano.

\section{EL CONTEXTO INTERNACIONAL DEL CLIMA DE INVERSIÓN}

Así como el gran filósofo español Ortega y Gasset dijo "Yo soy yo y mi circunstancia, y si no la salvo a ella no me salvo yo», las empresas también se definen por sí mismas y por sus circunstancias externas tanto del microentorno (consumidores, competidores, proveedores, facilitadores) como del macroentorno (sociales, económicas, políticas, tecnológicas y ecológicas). Ergo, el reto de los emprendedores es gestionar sus empresas con racionalidad económica y con adecuación y explotación proactiva de su entorno. En otras palabras, hacer negocios en general no es tan fácil. Esto obliga a dar un vistazo al gran panorama socioeconómico del mundo en desarrollo, como muy bien lo describe el Banco Mundial:

Ampliar las oportunidades para la gente de los países en desarrollo es una preocupación urgente para los gobiernos y para la comunidad global. Cerca de la mitad de la población del mundo vive con menos de dos dólares al día, y mil cien millones de personas a duras penas sobreviven con menos de un dólar al día. Los jóvenes han más que duplicado la tasa promedio de desempleo en todas las regiones, mientras, durante los próximos treinta años, el crecimiento de la población agregará cerca de dos mil millones de personas a los países en desarrollo. Mejorar el clima de inversión en estos países es fundamental para ofrecer empleos y oportunidades para los jóvenes y para construir un mundo más incluyente, más equilibrado y más pacífico (2004: XIII).

Pero, según el Banco Mundial, hay buenas y malas noticias:

Buena noticia:

Un mayor número de gobiernos son conscientes de que sus políticas y comportamientos cumplen una función vital para crear los climas de inversión de sus sociedades y están introduciendo cambios. China e India ofrecen dos ejemplos convincentes... (2004: XIII)

\section{Mala noticia:}

Los gobiernos continúan imponiendo costos innecesarios sobre las empresas y los empresarios, creando gran incertidumbre y riesgos significativos y levantando barreras injustificadas a la competencia (2004: XIII). 
Dado este gran contexto, el Banco Mundial, en el informe del que se toman estas citas, establece cuatro propuestas, que se señalan a continuación:

... [1] la meta debería ser un clima de inversión que sea mejor para todos -en dos dimensiones. Debe favorecer a la sociedad en su conjunto, no solamente a las empresas. Una normatividad y una tributación bien diseñadas son, por tanto, parte importante de un clima de inversión adecuado. $Y$ debe abarcar a empresas de todos los tipos, no solamente las grandes o influyentes. Todas, empresas pequeñas y grandes, locales y foráneas, y las de baja y alta tecnología, tienen importantes aportes adicionales que hacer al crecimiento y a la reducción de la pobreza [...] [2] los esfuerzos para mejorar el clima de inversión deben trascender la simple reducción de los costos del negocio. Estos costos pueden ser en realidad extraordinarios en muchos países, ascendiendo a muchísimo más de lo que las empresas pagan por concepto de impuestos. Pero los riesgos relacionados con las políticas dominan las preocupaciones de las empresas en los países en desarrollo y pueden perjudicar los incentivos a la inversión. $Y$ las barreras a la competencia continúan siendo omnipresentes, entorpeciendo los incentivos para que las empresas innoven y aumenten la productividad. Los gobiernos deben abordar los tres aspectos de un clima de inversión adecuado. [...] [3] para avanzar, se necesita algo más que cambios en las políticas formales. Las brechas entre las políticas y su puesta en práctica pueden ser enormes, y las inmensas economías informales de muchos países en desarrollo proporcionan la evidencia más palpable. Los gobiernos deben cerrar estas brechas y resolver fuentes profundas de fracasos de políticas que pueden socavar un clima de inversión sano. Los gobiernos deben resolver el problema de la corrupción y otros métodos de búsqueda de rentas, para crear credibilidad con las empresas, para fomentar la confianza pública y la legitimidad, y para garantizar que sus mediaciones de políticas hayan sido diseñadas para ajustarse a las condiciones locales. [...] [4] [se requieren] estrategias para abordar una agenda de tal magnitud [...] no se requiere la perfección y [...] no es necesario que todas las cosas se hagan de inmediato. Pero lograr avances exige que los gobiernos aborden restricciones importantes de manera que produzcan en las empresas la confianza para invertir -y para sustentar un proceso de mejoras permanentes. La persistencia tiene compensaciones (2004: XIII y XIV).

Como podrá observarse, hay mucho por hacer desde el punto de vista de la sociedad y los gobiernos. Es de esperar que los países en desarrollo tracen sus propios caminos hacia su desarrollo sostenible e inclusivo, y afrontando de la mejor manera sus circunstan- cias, muy bien descritas por el Banco Mundial porque, en caso contrario, siempre parafraseando a Ortega y Gasset, si los países en desarrollo no logran ser lo que deben ser con su propia circunstancia, si no logran salvarla, no se salvarán ellos.

Retomando el camino de la inversión y el desarrollo del espíritu emprendedor para la mejora de los países en desarrollo, como ya se ha indicado líneas arriba, uno de los instrumentos a la medida de los retos actuales es el modelo empresarial de franquicias que, precisamente, por su propia naturaleza es a) para espíritus emprendedores tangibilizados y b) para pequeñas y microempresas.

En consecuencia, el puente básico para la propuesta de desarrollo de formatos empresariales de franquicia es el análisis del contexto, mejor dicho, de la realidad actual del sector de las pequeñas y microempresas.

\section{EL CONTEXTO GENERAL DE LAS PEQUEÑAS Y MICROEMPRESAS EMPRENDEDORAS}

En el entendido que este es un documento de enfoque práctico que postula «tangibilizar» el espíritu emprendedor, no profundiza en análisis y conceptualizaciones ya efectuadas por reputados analistas, centros de investigación, instituciones académicas y otros. De ellos, más bien, se recogen ideas y planteamientos resultados de sólidas investigaciones.

\section{Políticas de desarrollo de la pequeña y microempresa}

Fernando Villarán ${ }^{1}$ plantea cinco tesis para el desarrollo de la pequeña empresa:

a. El sector privado es el protagonista del desarrollo económico [...]

b. Ni Estado-papá ni Estado-ausente. Se requiere un Estado-socio [...]

1. Riqueza popular: visión y gloria de la pequeña empresa. (1998). Lima: Congreso de la República del Perú.El primer punto de la parte IV de este libro, «Políticas de desarrollo de la pequeña empresa», está indicado por el autor como documento inédito que sirvió de base para la presentación de Visión estratégica para el desarrollo de la pequeña empresa, del Comité de la Pequeña Industria de la SNI, dentro de un proyecto financiado por la GTZ en 1997. 
C. El sector privado es uno solo [...]

d. Cierta informalidad representa una traba para el desarrollo del sector [...]

e. La solución a los problemas de la pequeña empresa se encuentra fuera del sector (1998: 265-290).

Las cinco tesis son analizadas y demostradas por Villarán en el documento indicado, pero es importante citar su invocación siguiente:

El mensaje a las empresas y a las personas es claro: desarrollen tecnologías, exporten, inviertan, creen nuevas empresas en la seguridad de que van a obtener algún tipo de apoyo del Estado. El mensaje para la juventud es también claro: vuelquen su energía, su creatividad y su entusiasmo a pensar y crear empresas, a participar en las existentes que están comprometidas con estas líneas de acción. El país entero se ve convocado a un esfuerzo nacional por desarrollar tecnologías, por asimilar las externas, por conquistar mercados en el exterior, por crear empresas competitivas y con posibilidades de crecimiento. En este sentido pensaremos que se puede hablar de una agenda del país para el siglo XXI (1998: 290).

\section{Los cinco misterios del capital}

En su famoso libro El misterio del capital, Hernando de Soto (2001) plantea precisamente los cinco misterios del capital:

- El misterio de la información ausente.

- El misterio del capital.

- El misterio de la conciencia política.

- Las lecciones no aprendidas de la historia de Estados Unidos.

- El misterio del fracaso legal: por qué la ley de propiedad no funciona fuera de Occidente.

Los cinco misterios son sólidamente analizados por De soto, pero es siempre reconfortante releer la cita al inicio del análisis del segundo misterio, el del capital:

El sentido del mundo debe quedar fuera del mundo. En el mundo todo es como es y sucede como sucede: en él no hay ningún valor $-\mathrm{y}$ aunque lo hubiese, no tendría ningún valor.

Si hay un valor que tenga valor, debe quedar fuera de todo lo que ocurre y de todo ser así. Pues todo lo que ocurre y todo ser así son casuales.
Lo que lo hace no casual no puede quedar en el mundo, pues de otro modo sería a su vez casual.

Debe quedar fuera del mundo.

Ludwig Wittgenstein. Tractatus Logico-Philosophicus (De Soto: 2001: 58)

\section{Cómo crecer para aprovechar las oportunidades doradas}

Sull y Wang (2006), luego de analizar conceptual y casuísticamente lo que se puede aprender de los empresarios chinos, plantean sus conclusiones, a las que denominan: «Cómo crecer para aprovechar las oportunidades doradas»:

- Crecer con eficacia se refiere al aumento de la escala de una organización para satisfacer con rapidez las crecientes demandas de los clientes y llenar una brecha en el mercado antes que los competidores se apresuren a entrar. El crecimiento acelerado de los ingresos pone presiones sobre los recursos de una compañía y exige cuidadosa administración. Ejercer la disciplina de mantener un foco de concentración claro es crucial para crecer correctamente.

- Estandarizar lo importante. Al pasar las compañías más allá del período inicial de experimentación, los procesos ad hoc para la fase inicial fallan bajo la presión del crecimiento rápido al aumentar de escala. Los gerentes deben establecer sistemas estandarizados que, de manera sistemática y confiable, desempeñen operaciones de rutina sin necesidad de atención de parte de los altos ejecutivos. Los ejecutivos deben estandarizar cinco dimensiones: procesos clave, marcos estratégicos, recursos, relaciones y cultura.

- Las restricciones inevitables son cuellos de botella potenciales que pueden impedir del todo a una compañía aumentar su escala. Algunas de tales restricciones inevitables son comunes entre las compañías, entre ellas la disponibilidad de fondos y la capacidad del equipo de alta gerencia de hacer frente a los grandes problemas de la firma. Otras son específicas de una compañía y con frecuencia sorprenden. Surgen de fuentes idiosincrásicas, como la evolución de la tecnología pertinente o la capacidad de crecer de socios específicos.

- Aun cuando los empresarios manejen con cuidado el proceso de crecer, las firmas van a enfrentar desafíos imprevistos al hacerlo. Los gerentes prudentes desarrollan barreras contra las contingencias imprevistas, entre ellas la creación de un fondo de guerra con dinero excedente, el mantenimiento de la disciplina operativa y financiera, la alineación de socios poderosos como parte del éxito 
de la firma, y el tener la seguridad de que los propietarios y los propios gerentes están dispuestos a dar el salto y permanecer con la compañía para el gran viaje. (2006: 271-272).

\section{Emprendedorismo (entrepreneurship) y competencias empresariales}

Sobre el punto, hay mucha investigación efectuada y publicada. El autor se ha permitido hacer una breve selección de referencias, que considera faros importantes para avanzar hacia el gran objetivo: mejorar u optimizar la competitividad internacional de los países de América Latina, como medio, y el desarrollo sostenible, como fin. A continuación, las referencias:

a) Emprendedorismo. ¿Qué es el espíritu emprendedor? Villarán (2002: 3-4) considera que son tres los temas «vinculados con la actitud emprendedora, llamada también emprendedorismo, empresarialidad o espíritu emprendedor, y que en inglés se denomina entrepreneurship....:

... [1] una visión general de la economía en la sociedad del siglo XXI [...] contexto actual y lo que nos espera en el futuro. [...] [2] la pequeña empresa, cuya presencia es una de las características de la economía de este siglo y guarda relación, obviamente, con la apertura de oportunidades para los emprendedores. La pequeña empresa es, normalmente, el primer paso para muchos emprendedores. [...] [3] las fuerzas motrices o dinamizadoras de la economía...

b) Factores de éxito del emprendedorismo. En cuanto al emprendorismo, Villarán, ya como tema central de la misma exposición, plantea y explica con detalle las variables explicativas de este y en qué estudio se sustentan:

... resultado de la investigación internacional sobre el emprendorismo, realizada en dos etapas, la primera entre enero y mayo del 2000 y la segunda entre noviembre del 2000 y marzo del 2001. La investigación es un estudio comparativo entre cuatro países latinoamericanos y cuatro países asiáticos cuyo objetivo fue identificar los factores que influyen en el proceso emprendedor y encontrar las razones por la cuales algunos países son más emprendedores o tienen mayor número de empresas (2002: 13-14).

Los factores de éxito o variables concluyentes del estudio indicado fueron:

- Experiencia previa.
- Relaciones comerciales y personales.

- Background del emprendedor o de la emprendedora.

- Cultura emprendedora.

- Educación emprendedora.

- Valores no monetarios.

c) Emprendedores e intraemprendedores. Casi todo lo escrito sobre espíritu emprendedor se refiere al tema de manera general o fraccionada en subtemas, pero explícitamente no se ha desarrollado con fuerza un elemento vital del emprendedorismo y de su tangibilización: el o los intraemprendedores. En este sentido, cabe citar a Pedro Nueno, quien expresa lo siguiente:

La gran mayoría de las empresas nacen porque un emprendedor (en realidad con frecuencia es un pequeño grupo, dos o tres emprendedores) descubre la oportunidad, concibe el proyecto y lo pone en práctica. Pero hay un cierto número de empresas que nacen por iniciativa de ejecutivos de empresa o incluso de políticos. Unión Fenosa, una compañía eléctrica, desarrolló en su interior un equipo de consultoría para mejora de los procesos. Posteriormente, pidió a ese grupo que trabajase para clientes externos. Más adelante, en el año 2000, segregó toda esta actividad, que ocupaba ya a 4.000 personas, y la incorporó como una empresa independiente con el nombre Soluziona. En 2004, con ventas [de] alrededor de 800 millones de euros, y más de 8.000 empleados en 28 países, Soluziona era una gran empresa de servicios profesionales y Unión Fenosa se planteaba desinvertir vía su salida a Bolsa o su venta. Éste sería un ejemplo claro de generación de una gran nueva empresa desde dentro de una empresa. [...]. En la bibliografía de la iniciativa empresarial suele llamarse intraemprendedor al directivo que crea nuevas empresas desde su responsabilidad dentro de una empresa. Los procesos de emprender e intraemprender tienen muchos elementos en común... (2005: 19-20).

\section{Competencias gerenciales, competitividad}

a) Competencias generales necesarias para crear y gestionar exitosamente pequeñas y microempresas. El Programa Especial Mejoramiento de la Calidad de la Educación Peruana (Mecep) del Ministerio de Educación (2001), como resultado de su investigación sobre competencias generales empresariales, plantea las siguientes, como características del emprendedor competitivo y de éxito: 
1. Tiene capacidad de comunicación fluida y empática, lo que optimiza el servicio al cliente, la satisfacción del personal y las buenas relaciones con los proveedores. [...]

2. Posee iniciativa y capacidad para tomar decisiones en situaciones normales o de riesgo, y asume permanentemente nuevos desafíos empresariales. [...]

3. Resuelve problemas, busca permanentemente soluciones creativas, tiene vocación por la innovación, el cambio y la mejora continua en todos los ámbitos de su empresa. [...]

4. Actúa en función de valores, comprometiendo las voluntades de colaboradores, clientes y proveedores, y generando una cultura empresarial propia. [...]

5. Obtiene, interpreta y establece prioridades en la información, demostrando dominio y actualización de conocimientos necesarios para el desarrollo de la empresa. [...]

6. Desarrolla métodos de trabajo sistemáticos, organiza las funciones y áreas de su empresa, y controla todos los procesos de su actividad empresarial. [...]

7. Orienta sus esfuerzos hacia la generación de riqueza, tiene vocación por el ahorro y la inversión, y actúa guiado por una racionalidad económica, planteándose constantemente metas de crecimiento. (Ministerio de Educación, 2001: 23-25).

b) Competitividad responsable. En el tema de la competitividad, para los fines de este trabajo, no puede dejarse de lado la responsabilidad social y, muy especialmente, cuando se está proponiendo un sistema empresarial para pequeños y microempresarios a quienes, en muchos casos, no se les mentaliza respecto de sus obligaciones para con la sociedad, a despecho de que ellos hacen por iniciativa propia muchas prácticas de índole social.

También como otro elemento contextual y conceptual de este trabajo, es meritorio el aporte siguiente (Acuerdos para competir, 2007: 56-57):

Competencia responsable. Es un tema que no aparece casi nunca en los programas de responsabilidad social empresarial, RSE, pero que debería estar porque la acción con los competidores afecta la relación con los demás grupos de interés, consumidores, empleados y accionistas. De hecho, ellos mismos son un grupo de interés importante. [...] La responsabilidad social corporativa es la capacidad que tiene una empresa de asumir como propias las consecuencias de sus actos y prever el efecto positivo o negativo que tendrán en los diferentes grupos de interés (stakeholders)» señala el consultor de RSE, Rafael Mateus, de la firma Vortex. Para prever esos efectos, los posprogra- mas deben incluir el tema de las empresas que conforman la competencia comercial.

De lo expuesto en esta parte, sobre el contexto general de las pequeñas y microempresas emprendedoras, que ex profesamente tiene cierto grado de detalle, se puede concluir en lo siguiente:

- El contexto internacional del clima de inversión es favorable para las empresas en general y para las pequeñas y microempresas en particular.

- Los gobiernos, en general, cada vez son más conscientes de que sus políticas y comportamientos cumplen una función vital para crear los climas de inversión de sus sociedades y están introduciendo cambios. Son dignas de atención las experiencias de China e India.

- Es fundamental desarrollar y/o despertar el espíritu emprendedor en los países en vías de desarrollo, especialmente los latinoamericanos, pero con altos niveles de competitividad, definido comportamiento social responsable y clara vocación de desarrollo sostenible.

- Debe explicitarse o tratar con más evidencia y fuerza el espíritu intraemprendedor.

- La consecuencia de todo ello va a ser una sólida «tangibilización» del espíritu emprendedor. El mensaje es que no todo sea bonita retórica empresarial escrita, como aparentemente pudiera ser, salvo mejor opinión.

Por lo tanto, con esta base, se propone a continuación el formato empresarial de franquicias como estratégico, inmediato y moderno sistema de negocios a la medida de los pequeños y microemprendedores.

\section{EL FORMATO EMPRESARIAL DE FRANQUICIAS: MODERNO SISTEMA DE NEGOCIOS QUE TANGIBILIZA EL ESPÍRITU EMPRENDEDOR ${ }^{2}$}

El término „franquicia« está haciéndose cada vez más conocido en nuestros países y eso está muy bien. Sin

2. El desarrollo de esta segunda parte del presente documento se basa en el libro Franquicias: opción de desarrollo estratégico, del autor (Gastañaduy, 2000). 
embargo, se percibe que comienza a haber cierta confusión en lo que ello significa. Para comenzar, no se le debe considerar como una «moda» que hay que seguir porque hay que seguir. Sucede que, por la globalización, en América Latina recién se están comenzando a percibir, con mayor claridad y desde una perspectiva de modernidad económica, los negocios más allá de las fronteras de nuestro subcontinente.

Ello también está permitiendo crear las condiciones para que se suelten las verdaderas fuerzas y energías productivas de los países en el corto plazo y se comience a vivir un periodo de reactivación económica general en Latinoamérica.

Por la reducción arancelaria en los países antes sobreprotegidos se ha desarrollado rápidamente el comercio de bienes importados, en desmedro de la industria local. Por falta de competitividad internacional o por la recesión económica, muchas empresas han cerrado, y las que han seguido operando simplemente se han visto obligadas a ser iguales o mejores que sus competidores internacionales.

En este contexto, para el caso del negocio de franquicias se presentan dos grandes campos de oportunidades: la importación de franquicias y el desarrollo de franquicias locales. Antes de comentarlos, es preciso efectuar algunas consideraciones previas sobre este sistema de hacer negocios.

\section{Qué es la franquicia}

A este respecto, hay que tener en cuenta dos grandes tipos de concepciones, pues la franquicia no es algo tan nuevo, se ha hecho desde la Edad Media. Explícitamente y como negocio, viene desde el siglo pasado y se ha ido modernizando con el transcurso del tiempo. De ahí que en el mundo empresarial contemporáneo haya dos enfoques: el clásico y el moderno.

En el enfoque clásico, el fabricante o distribuidor titular de la marca vende sus productos al comerciante (su revendedor autorizado), el cual simplemente los revende a un precio más alto. El titular de la marca casi siempre autoriza al revendedor a hacer uso de esta y puede, asimismo, ofrecer algún entrenamiento y algún esquema de publicidad que ayude al revendedor a vender más. No exige, por ello, que el revendedor siga un esquema rígido de adaptación en la operación de su propio negocio. Aquí pueden identificarse, a su vez, tres modalidades diferentes de hacer franquicias:

- Franquicia fabricante-minorista. Incluye, por ejemplo, a los fabricantes de automóviles y sus minoristas; a los comercializadores de petróleogasolina-gas y sus minoristas y algunos otros pequeños grupos. Este es verdaderamente el grupo combustible-automovilístico de establecimientos franquiciados, que en nuestro medio son más conocidos como "concesionarios»: Mitsubishi, Ford, Volkswagen, Toyota, etc., para el caso de autos; $y$ los establecimientos Texaco, Primax, Móbil, Repsol, etc., para el caso de los combustibles.

- Franquicias fabricante-mayorista. Este es el tipo de franquicias originado por marcas como Coca Cola, Pepsi Cola y otras marcas famosas de bebidas gaseosas. Este tipo de sistema es importante, pero con un número relativamente pequeño de unidades. En nuestro medio adopta el nombre de «embotellador autorizado». La embotelladora, que hace a su vez un proceso industrial, funge como mayorista para una zona geográfica determinada.

- Franquicias mayorista-minorista. Incluye cadenas ferreteras, de abarrotes, de repuestos para automóviles, entre otras. Las cadenas de llantas para vehículos son un importante segmento de este tipo de franquicias. Además de neumáticos y accesorios para automóviles, están dentro de este grupo los implementos para el hogar, algunos equipos deportivos, herramientas para conservación de jardines, bicicletas, etc. También son conocidos como «concesionarios» o «distribuidores autorizados».

En el enfoque moderno, también conocido como business format franchising (franquicia de formato empresarial), existe una relación contractual entre el franquiciador (el otorgante) y el franquiciado (el que 
recibe $)^{3}$, por la cual el primero se obliga a mantener un interés continuo en el negocio del segundo, tanto en know how como en entrenamiento.

Este sistema se utiliza como estrategia de desarroIlo empresarial, formando alianzas estratégicas a partir del desarrollo de un sistema estandarizable y explotado con una marca o insignia muy bien posicionada en el mercado. Se utiliza en estrategias de extensión de mercados y, especialmente, para bienes y servicios de consumo masivo. El franquiciado opera bajo un nombre comercial común y un formato y un procedimiento establecidos o controlados por el franquiciador; además, el franquiciado efectúa una sustancial inversión de capital en su negocio, de su propio peculio. $Y$ esta modalidad de enfoque moderno, que realmente está revolucionando el mundo de los negocios, es la que más se conoce simplemente como sistema de franquicias y puede comenzar a confundirse con las tres modalidades clásicas (especialmente con la de mayorista-minorista).

Este sistema ha crecido mucho en las últimas décadas en los Estados Unidos, Europa y Oriente y está penetrando en mercados de países emergentes; en América Latina, Brasil y México fundamentalmente. En este sistema, el franquiciador raramente es un fabricante $y$ usualmente no es un mayorista. Generalmente hay un nombre comercial común y métodos estandarizados (o business format franchising, como es frecuentemente denominado) para la operación exitosa de unidades minoristas. Las unidades minoristas deben mercadear un producto o grupo de productos, un servicio o grupo de servicios, o alguna combinación de ellos bajo un nombre comercial común. La arquitectura de estas unidades es usualmente estandarizada, así como su mecánica operativa.

Como referencia, algunas de las más conocidas franquicias en Estados Unidos con este sistema son: Cadenas de hoteles, como Holiday Inn, Sheraton Inn,

3. En el diccionario de la RAE (Real Academia Española) no figuran los términos «franquiciante» 0 «franquiciador» (otorgante de la franquicia), ni «franquiciado» (quien recibe la franquicia). Para fines del presente trabajo, el autor utilizará los términos «franquiciador» $y$ «franquiciado», como ya se ha explicado.
Quality Courts; cadenas de restaurantes, como Howard Johnson's, Mister Donut, McDonald's, Kentucky Fried Chicken, Dunkin's, Donuts, Burger King, Burger Chef, Wimpy's, A \& W, Baskin Robbins, Wendy's, Pizza Hut; empresas de alquiler de vehículos, como Hertz, Avis, Budget Rent-A-Car, entre otras.

\section{Por qué se hacen negocios de franquicias}

Por su propia naturaleza, como se indicó anteriormente, la franquicia es un sistema empresarial que busca resolver problemas de mercadeo masivo, atender necesidades generales y no precisamente específicas. Se aplica más en casos de distribución extensiva.

En este quehacer, las empresas que venden bienes y servicios masivos llegan a un punto tal en que deben resolver, sobre todo, problemas de índole interna y de «costo de agencia».

Entre los problemas de índole interna se pueden mencionar, básicamente, los sistemas de incentivos y la necesidad de supervisión dentro de la empresa, para que los administradores cumplan su función con eficiencia. Además, estos problemas son cada vez más relevantes en la medida en que crecen los mercados y/o aumenta el nivel de competencia.

En cuanto a los costos de agencia, los cuatro grandes problemas son: ineficiencia en la asunción de riesgo, consumo de beneficios no pecuniarios y/o poco esmero en el trabajo, apropiación de cuasi renta y «free rider» (cuando los incentivos de no cumplir el acuerdo son mayores que el castigo de ser sorprendido). Del análisis de estos problemas, que escapa al alcance de este artículo, se concluye que puede convenir - o no- el optar por la franquicia como estrategia de desarrollo empresarial.

Este conjunto de facilidades de desarrollo empresarial de mercadeo masivo, así como la eficiente gestión de sus inherentes problemas de incentivo-supervisión y de costos potenciales, explican el porqué se desarrollan franquicias y cada vez con más fuerza. De otro lado, también permiten entender que la franquicia no siempre sea deseable en todos los casos. Para ello existen diversas metodologías de análisis de franquiciabili- 
dad que, luego de aplicarse a las empresas interesadas, pueden confirmar o no la posibilidad del desarrollo del negocio como franquicia.

\section{Cómo se hace o desarrolla un negocio con franquicia}

Después que una empresa ha sido evaluada como franquiciable y decide que el sistema de franquicias es su opción de desarrollo estratégico para maximizar la rentabilidad de su inversión, su siguiente paso es la fase de planeamiento. Para ello, debe efectuar un prolijo trabajo de ingeniería comercial a fin de tener absoluta claridad al entrar al ciclo de coronación del éxito en el formato empresarial de franquicias o business format franchising.

A continuación, la «receta» mágica:

1) Diagnóstico previo

2) Estudio de mercado

3) Análisis estratégico de franquiciabilidad

4) Presentación de resultados y definición de objetivos y criterios para el planeamiento estratégico

5) Planeamiento estratégico del sistema de franquicias

6) Desarrollo del concepto de negocio

7) Desarrollo e instalación de una o más unidades piloto

8) Desarrollo del pack de franquicias

9) Diseño del programa de capacitación

10) El management plan de la franquicia

11) El contrato de franquicia

12) El plan de ventas de la franquicia

\section{Campos de oportunidad con el formato empresarial de franquicias: importación de franquicias y desarrollo de franquicias locales}

Ahora que ya se tiene una clara idea de lo que significa la franquicia, serán más fáciles de explicar las grandes oportunidades que se están presentando para quienes puedan tener recursos y deseos de invertir en su país. Independientemente de la coyuntura favorable o des- favorable, ya en el tercer milenio, el entorno para hacer negocios en los países de América Latina comienza a ser previsto por muchos analistas como ventajoso en el corto plazo.

\section{Importación de franquicias}

Una primera evidencia es la importación de franquicias de los Estados Unidos, pues preferentemente en este país se han desarrollado miles de sistemas de franquicias que no solo guardan relación con negocios muy conocidos, como los de fast food o comida rápida: KFC o Pizza Hut, por ejemplo. Hay franquicias prácticamente en todos los campos de la actividad humana, y conforme en nuestros países vayan dándose las condiciones adecuadas, tranquilamente podrán comenzar a operar franquicias en estos campos.

Si se revisa la revista estadounidense Entrepreneur ${ }^{4}$, podrá advertirse que hay franquicias en muchos sectores de negocios: entretenimiento y recreación, automovilismo, salud y belleza, productos y servicios para la construcción, servicios empresariales, servicios de provisión de personal, productos y servicios para niños, ropa y accesorios, computación, productos y servicios para la decoración, educación, pastelería y helados, comida rápida, bodegas-confiterías, hotelería, productos y servicios de mantenimiento, servicios para fiestas, mascotas, productos y servicios para fotografía y grabaciones, servicios de impresión y fotocopiado, publicaciones, bienes raíces, restaurantes, servicios minoristas, sistemas de seguridad, negocios de servicios generales, viajes.

Todos ellos agrupan múltiples empresas que han desarrollado nombres o marcas líderes en dicho país, pero no necesariamente son conocidas en todo el mundo, especialmente en América Latina. Al respecto, si algún inversionista latinoamericano se interesa en importar alguna franquicia norteamericana, fundamentalmente debe tener un fuerte y positivo espíritu emprendedor; ello le permitirá racionalizar y conciliar tres grandes aspectos: que haya demanda local; que sea una marca o nombre conocido en su país o, en todo caso, se haga la

\footnotetext{
4. <http://www.entrepreneur.com/franchise500/index.html>.
} 
respectiva inversión publicitaria; y que él mismo (el importador) cuente con los recursos financieros del caso.

La opción de importación es buena, pero luego de los análisis empresarial y del contexto. Obviamente, siempre será recomendable asesorarse bien y encargar un completo estudio del mercado.

\section{Desarrollo de franquicias locales}

En los países latinoamericanos hay muchos grupos de negocios que atienden necesidades masivas de la población y que muy bien podrían calificar como franquiciables. Algunas empresas ya han posicionado bastante bien sus nombres comerciales, lo que les puede facilitar dar el gran salto. Hay ramos donde el potencial franquiciable es grande, como por ejemplo: cafés, farmacias, panaderías, pastelerías, heladerías, restaurantes de pollos a la brasa, pizzerías, snacks, carnicerías, lavanderías, gimnasios, escuelas de mando medio (idiomas, secretariado, computación, modelaje, entre otras), peluquerías (varones, mujeres, unisex), centros de estéti$\mathrm{ca}$, boutiques, perfumerías, servicios de limpieza (casas, oficinas, industrias), ópticas, hotelería, venta de bienes y servicios para la construcción, ferreterías, supermercados, minimercados, bodegas, seguridad, venta de artículos para el hogar, ropa y artículos deportivos, etc. También hay hasta franquicias bancarias, cuya explicación escapa a este trabajo.

Incluso, puede pensarse en actividades tales como estudios jurídicos, institutos odontológicos, centros médicos, de homeopatía o de medicina natural, en las que el posicionamiento reside más en la calidad o atributos buscados por el usuario que en las personas o especialistas que están al frente de las instituciones. Hasta el mismo servicio postal podría adoptar el business format franchising.

En consecuencia, para que todas estas actividades puedan activarse y desarrollarse, especialmente con el sistema de franquicias con formato empresarial, lo fundamental es que el mercado se comience a activar, y ello se dará con el inicio de la reactivación económica del país del que se trate, con la creación de un en- torno favorable tanto para el consumo como para la inversión. Si la capacidad de consumo de la población comienza a mejorar, inmediatamente se habrá iniciado la era del franchising en nuestros países. Los hombres de negocios con mentalidad moderna, con verdadero espíritu emprendedor, entonces, no tienen tiempo que perder desde ahora.

\section{CONCLUSIÓN}

La suerte está echada. No hay tiempo que perder. El terreno está prácticamente listo.

Las responsabilidades, en opinión del autor, y en orden de prioridad, son las siguientes:

1) Las instituciones académicas. Sus expertos son los más informados acerca de los mejores métodos de atender empresarialmente las necesidades y problemas de las personas, las empresas y la sociedad en general.

2) Los gobiernos. Simplemente deben ser cada vez más promotores e incentivadores del esfuerzo privado, sin descuidar sus responsabilidades de buscar el bienestar general de la población con desarrollo sostenible.

3) Las empresas en general. Que deben ser emprendedoras, proactivas, competitivas, orientadas al mercado, y operar con gestión moderna (racionalidad económica o eficiencia), comportamiento socialmente responsable y visión internacional. Estas también deben ser las principales características de las pequeñas empresas y los micronegocios.

Es necesario «tangibilizar» el espíritu emprendedor en el sector de la pequeña y microempresa. Entre los diversos medios o instrumentos prácticos e inmediatos para ello, es muy recomendable el formato empresarial de franquicias, por ser ya exitosamente maduro en los países desarrollados y en algunos en vías de desarrollo; estas experiencias le dan a la franquicia el benchmark necesario para adecuar los factores de éxito de este sistema a nuestros países. 


\section{Referencias bibliográficas}

Acuerdos para competir responsablemente. (2007, marzo). Dinero (Bogotá), 272, 56-57.

Banco Mundial. (2004). Informe sobre el desarrollo mundial 2005: un mejor clima de inversión para todos. Washington D. C. : Banco Mundial en coedición con MundiPrensa Libros y Alfaomega Colombiana.

Gastañaduy, Alfonso. (2000). Franquicias: opción de desarrollo estratégico. Lima:ESAN.

Nueno, Pedro. (2005). Emprendiendo hacia el 2010: una renovada perspectiva global del arte de crear empresas y sus artistas. Barcelona: Deusto.

Programa Especial Mejoramiento de la Calidad de la Educación Peruana (Mecep). (2001). Competencias necesarias para la creación y gestión exitosa de pequeñas y microempresas en el Perú. Lima: Ministerio de Educación. Documento de Trabajo 1.
Soto, Hernando de. (2001). El misterio del capital: por qué el capitalismo triunfa en Occidente y fracasa en el resto del mundo. Barcelona: Ediciones Península (Edición original: The mystery of capital: Why capitalism triumphs in the West and fails everywhere else. London: Bantam Press, Random House, 2000).

Sull, Donald N. \& Wang, Yong. (2006). Made in China: que podemos aprender de los empresarios chinos. Bogotá: Norma.

Villarán, Fernando. (1998). Riqueza popular: pasión y gloria de la pequeña empresa. Lima: Congreso de la República del Perú.

Villarán, Fernando. (2002). Condiciones para desarrollar el espíritu empresarial. Lima: ESAN (Conferencia ofrecida en ESAN el 13 de julio de 2002 durante el acto central del Día del Graduado). 
